Supplement of Biogeosciences, 13, 2405-2414, 2016

http://www.biogeosciences.net/13/2405/2016/

doi:10.5194/bg-13-2405-2016-supplement

(C) Author(s) 2016. CC Attribution 3.0 License.

(c) (i)

Supplement of

\title{
Differential responses of seabirds to environmental variability over 2 years in the continental shelf and oceanic habitats of southeastern Bering Sea
}

Takashi Yamamoto et al.

Correspondence to: Takashi Yamamoto (ytaka@nagoya-u.jp)

The copyright of individual parts of the supplement might differ from the CC-BY 3.0 licence. 

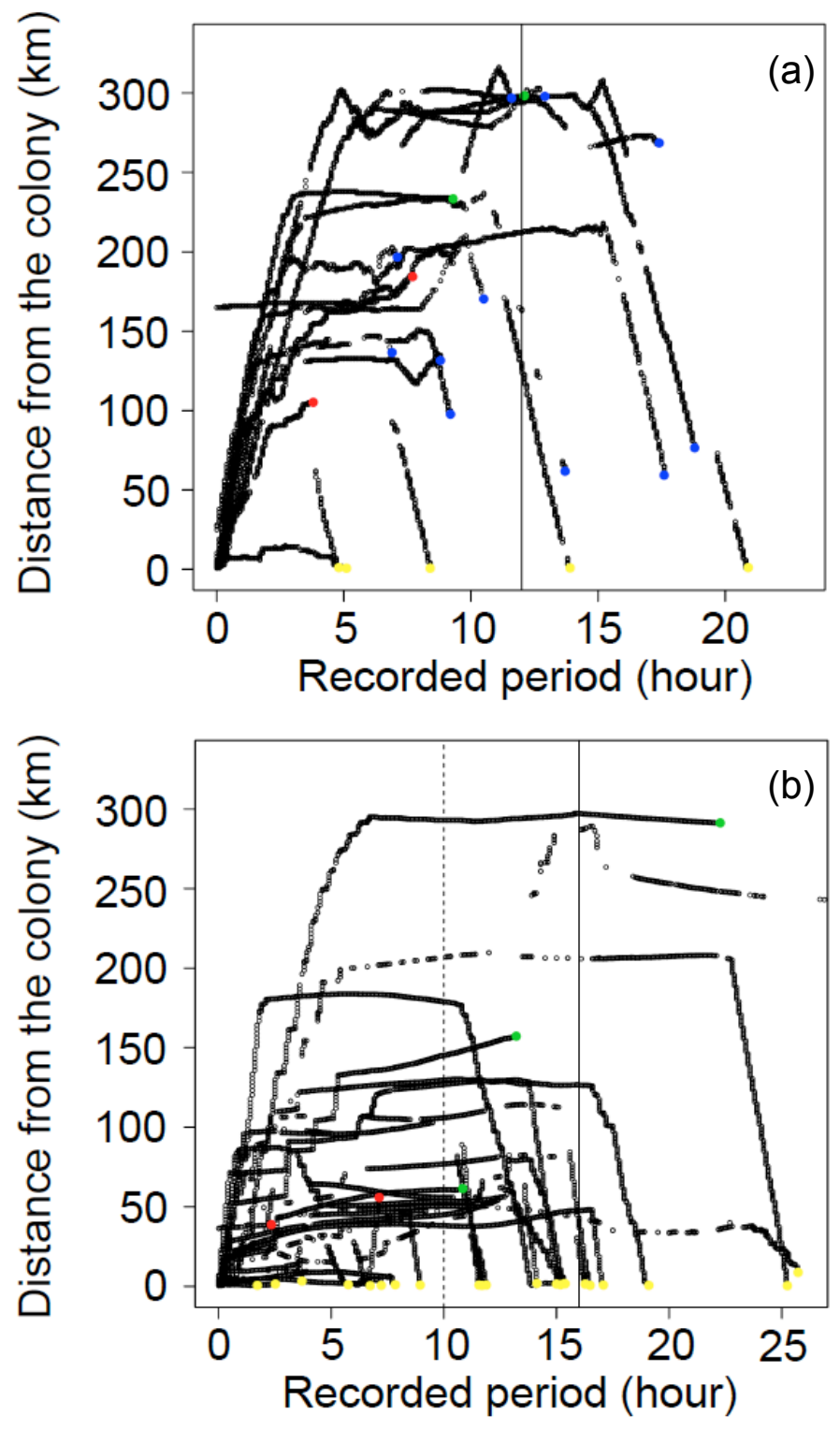

Figure S1. Longitudinal GPS fixes of red-legged kittiwakes (a) and thick-billed murres (b) relative to the distance from the colony; tracks recorded the complete trip (yellow dots), until close to the beginning of (green dots) or during the homing commute phase (blue dots), indicated as the continuous decrease in the distance from the colony (Weimerskirch 2007), and partial (red dots). 

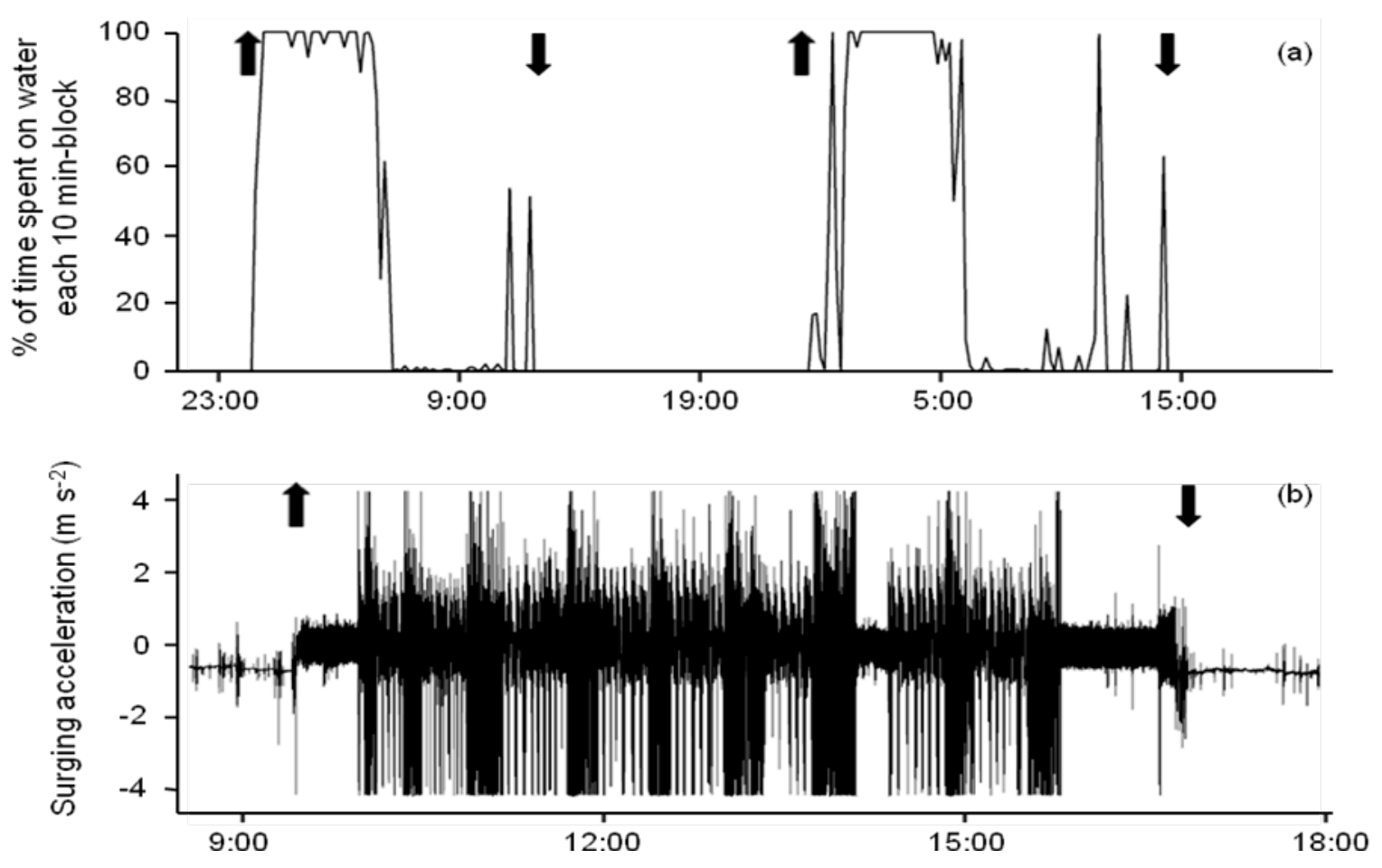

Figure S2. The definition of foraging trip durations of red-legged kittiwakes (a) and thick-billed murres (b), estimated using immersion loggers (i.e. geolocators) or accelerator loggers conducted concurrently (RLKI: 26 July-2 August, $\mathrm{n}=22$ trips in 2013 and 14 trips in 2014, TBMU: 31 July-12 August, $\mathrm{n}=9$ trips in 2013 and 21 trips in 2014). Upward and downward arrows indicate departure from and arrival at the breeding site, respectively. For the immersion data, the foraging trip duration was defined as the time between the first and last landing on water before and after long dry event which is likely underestimated, though comparable between the years. For the accelerometer data, it was defined as when vigorous accelerations occurred. 

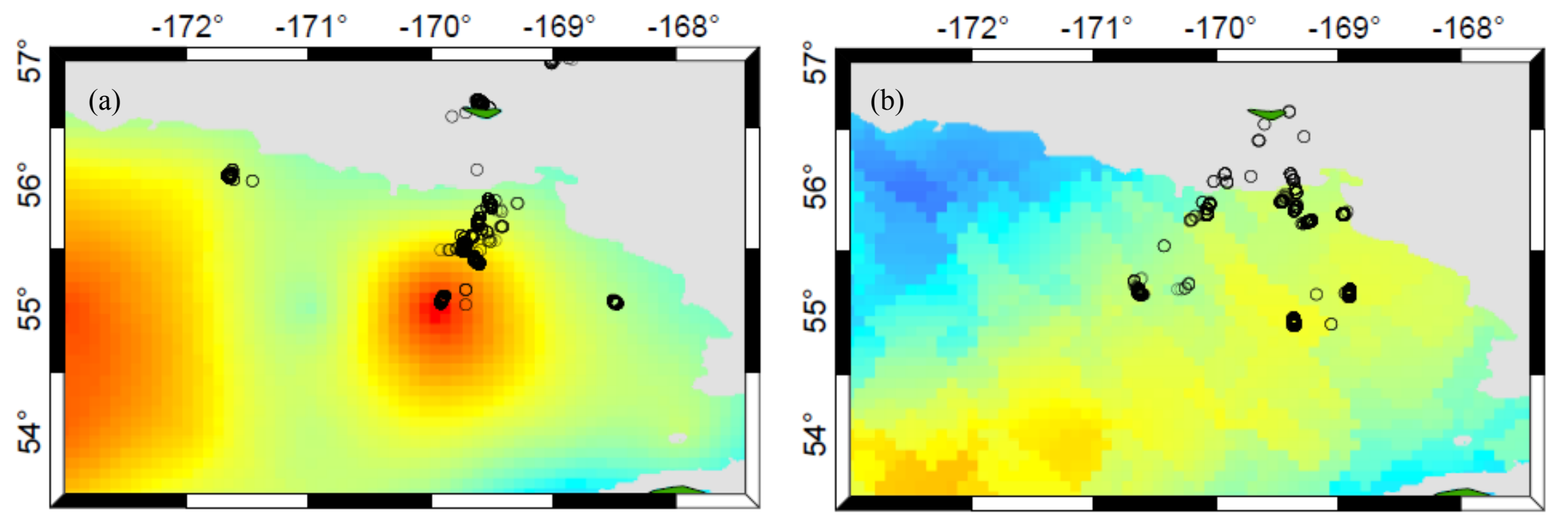

Figure S3. Foraging locations of red-legged kittiwakes overlaid on sea surface height anomaly (AVISO, monthly mean in August) in 2013 (a) and 2014 (b). Red color represents positive anomaly (upwelling as a proxy for anticyclonic eddies) and blue color represents negative anomaly (downwelling as a proxy for cyclonic eddes). 